\title{
Radiação UV-C sob a qualidade pós-colheita de jabuticaba
}

\section{Zeuxis Rosa Evangelista ${ }^{1}$, André José de Campos$^{2}$, Danilo Corrêa Silva², Kari Katiele Souza Araújo' $^{2}$, Luiz Fernandes Cardoso Campos $^{3}$}

${ }^{1}$ Universidade Federal de Goiás, Campus Samambaia, Goiânia, Goiás, Brasil. E-mail: zeuxisrosa@ hotmail.com

${ }^{2}$ Universidade Estadual de Goiás, Campus de Ciências Exatas e Tecnológicas, Anápolis, Goiás, Brasil. E-mail: andre.jose@ueg.br, bilo.ba@hotmail.com, kari.katiele@hotmail.com

${ }^{3}$ Universidade Estadual de Goiás, Campus de São Luís de Montes Belos, São Luís de Montes Belos, Goiás, Brasil. E-mail:

luizfernandescampos@hotmail.com

Recebido: 13/11/2017; Aceito: 26/11/2018.

\section{RESUMO}

O objetivo desse trabalho foi avaliar o efeito do tempo de exposição da radiação UV-C, na qualidade pós-colheita da jabuticaba 'Sabará'. O delineamento experimental foi inteiramente casualizado, com arranjo fatorial $5 \times 5$, sendo: tempo de exposição à UV-C $(0,2,4,6$ e 8 minutos $) \times$ dias de análise $(0,2,4,6$ e 8 dias de armazenamento), em três repetições. Após aplicação dos tratamentos, os frutos foram acondicionados em embalagens de polipropileno e armazenados a $12^{\circ} \mathrm{C}$, com $85-90 \%$ de UR. Foram avaliados perda de massa fresca, conservação pós-colheita, firmeza, sólidos solúveis, acidez titulável e pH. A utilização da radiação UV-C não interferiu positivamente na conservação da jabuticaba 'Sabará'.

Palavras-chave: armazenamento, atmosfera modificada, Myrciaria jaboticaba.

\section{UV-C radiation under post-harvest quality of jaboticaba}

\begin{abstract}
The objective of this work was to evaluate the effect of exposure time of UV-C radiation on the post-harvest quality of 'Sabará' or 'jabuticaba'. The experimental design was completely randomized, with factorial arrangement 5x5: five exposure time to UV-C $(0,2,4,6$ and 8 minutes) and five analysis days $(0,2,4,6$ and 8 days of storage) in three replicates. After application of the treatments the fruits were packed in polypropylene and stored at $12{ }^{\circ} \mathrm{C}$, with $85-90 \% \mathrm{RH}$. Fresh weight loss, post-harvest preservation, firmness, soluble solids, titratable acidity, and $\mathrm{pH}$ were evaluated. The use of UV-C radiation did not positively interfere with the conservation of 'jabuticaba'.
\end{abstract}

Keywords: storage, modified atmosphere, Myrciaria jaboticaba. 


\section{Introdução}

A Myrciaria sp., conhecida popularmente como jabuticabeira, é uma fruteira originária da Mata Atlântica, do Centro-Sul do Brasil, sendo encontrada do extremo sul ao extremo norte do país (Alezandro et al., 2013). Pertencente à família Myrtaceae, a jabuticabeira é geralmente rústica, não muito exigente do ponto de vista climático e nutricional. Produz em todas as regiões do país, adaptando-se aos diversos tipos de solo e condições climáticas (Soares et al., 2001).

$\mathrm{O}$ fruto da jabuticabeira possui alto teor de carboidratos, vitaminas, fibras, ferro, cálcio e fósforo, além de ser rico em substâncias antioxidantes (Citadin et al., 2005), como taninos, ácido ascórbico, flavonoides e antocianina na casca (Danner et al., 2011), caracterizando assim a jabuticaba como um alimento funcional. Diante dessas características benéficas, preocupa-se o fato da rápida perecibilidade do fruto, necessitando, portando, de tecnologias que reduzam essa velocidade de senescência e que mantenham a qualidade das jabuticabas por maior tempo.

López-Malo e Palou (2005) ressaltam que a radiação ultravioleta C (UV-C) é eficiente na eliminação de bactérias, protozoários, algas, vírus e fungos, portanto, apresenta alto interesse pela área agroindustrial. $\mathrm{O}$ seu efeito depende do nível e da duração do tempo em que o alimento é exposto, e a sua eficiência depende da espécie da variedade irradiada (Sanchez et al., 2012; Fan et al., 2012; Ribeiro et al., 2012). A UV-C, sobretudo em doses baixas, é capaz de induzir efeitos benéficos num fenômeno chamado hormesis, que consiste em estimular respostas benéficas por níveis baixos dos estressores, que são, de outras formas, prejudiciais. A sua ação é limitada à idade do vegetal, nível de resistência fitopatológica e estádio de amadurecimento (Mercier et al., 2000). Keyser et al. (2008) relatam que a utilização da radiação UV-C apresenta grandes vantagens na conservação de alimentos; é um tratamento não térmico, não deixa cheiro no alimento irradiado, durante a execução não deixa subprodutos que são tóxicos ao consumo humano, é capaz de remover alguns compostos orgânicos, e ainda aumenta a atividade de enzimas antioxidantes, que, por sua vez, reduzem a velocidade de senescência (Alothman et al., 2009; Shen et al., 2013). Além de apresentar simplicidade na instalação e na operação, baixo contato do manuseador e o fato de não produzir efeito residual, só aumentam as vantagens que têm a técnica para a utilização em alimentos (Keyser et al. 2008; López-Malo e Palou, 2005).

Ao estudarem o efeito da UV-C em abacate 'Hass', Daiuto et al. (2013) observaram que a exposição dos frutos a 15 e 20 minutos evidenciaram maior conservação pós-colheita e menor perda de massa e de atividade respiratória. Binoti et al. (2013), estudando a influência da radiação UV-C na qualidade pós colheita do tomate 'Pizzadoro' orgânico, verificaram que a exposição dos frutos a 20 minutos levou à menor perda de massa fresca, menor atividade respiratória, maior tempo para o amadurecimento e maiores valores de índice de maturação. Cia et al. (2009), aplicando UV-C em uvas 'Niágara', evidenciaram eficiência da irradiação em bagas inoculadas com Colletotrichum gloesosporioides, tanto em temperatura ambiente como nas refrigeradas $\left(25 \pm 1^{\circ} \mathrm{C}\right.$ e $\left.1 \pm 1^{\circ} \mathrm{C}\right)$, respectivamente. Bartnicki et al. (2010) afirmaram que a UV-C controlou, em pós-colheita, Cryptosporiopsis perennans em maçãs.

$\mathrm{O}$ objetivo desse trabalho foi avaliar o efeito do tempo de exposição à radiação UV-C na qualidade póscolheita da jabuticaba 'Sabará'.

\section{Material e Métodos}

Os frutos de jabuticaba 'Sabará' utilizados na pesquisa foram colhidos na Fazenda e Vinícola Jabuticabal, município de Hidrolândia, Goiás. Os frutos foram colhidos completamente maduros e transportados até o laboratório de Secagem e Armazenamento de Produtos Vegetais da Universidade Estadual de Goiás, Campus de Ciências Exatas e Tecnológicas em Anápolis, Goiás. No laboratório, foram uniformizados quanto ao tamanho, ausência de defeitos físicos e mecânicos, e separados em lotes.

$\mathrm{O}$ delineamento experimental foi inteiramente casualizado, com arranjo fatorial $5 \times 5$, sendo: tempo de exposição à UV-C $(0,2,4,6$ e 8 minutos $) \mathrm{x}$ dias de análise (0, 2, 4, 6 e 8 dias de armazenamento), em três repetições. Foi construído um protótipo (Figura 1) com câmara cilíndrica de polímero plástico (polietileno) com um grupo de vinte lâmpadas germicidas sem filtro, sendo dez na parte superior e dez na parte inferior do irradiador, com 30 watts cada, ligadas em paralelo, com a estrutura de geometria $50 \times 50 \times 90 \mathrm{~cm}$ e tela trefilada galvanizada, dividindo o equipamento em parte superior e inferior.

Após a exposição à radiação, os frutos de cada tratamento foram colocados em embalagens de polipropileno com oito frutos cada para avaliação do armazenamento pós-colheita, sendo refrigerados e armazenados em B.O.D. a $12^{\circ} \mathrm{C}$, com 85-90\% de UR.

As características físico-químicas avaliadas foram: a) Perda de massa fresca, determinada pela diferença percentual entre a massa inicial e a massa final ao fim de cada dia de análise, utilizando balança de precisão (BL 3200H, carga máxima de $3200 \mathrm{~g}$ e mínima de $0,5 \mathrm{~g}$ ); b) Conservação pós-colheita, avaliando o número de dias em que as jabuticabas se conservaram em função da sua qualidade comercial;

c) Firmeza, determinada com o auxílio do texturômetro Brookfield - Texture Analyser CT3 50K, com a 
profundidade de penetração de $5 \mathrm{~mm}$ e velocidade de penetração de $6,9 \mathrm{~mm} \mathrm{~s}^{-1}$;

d) $\mathrm{pH}$, determinado seguindo as Normas Analíticas do Instituto Adolf Lutz (Zenebon et al., 2008);

e) Acidez titulável, determinada por titulação com $\mathrm{NaOH}$ a $0,1 \mathrm{~mol} \mathrm{~L}^{-1}$ até o pH entre 8,1 e 8,2, com resultado expresso em \% de ácido cítrico (Zenebon et al., 2008);

f) Teor de sólidos solúveis, medido em leitura refratométrica em ${ }^{\circ}$ Brix, a $20^{\circ} \mathrm{C}$, com refratômetro digital.

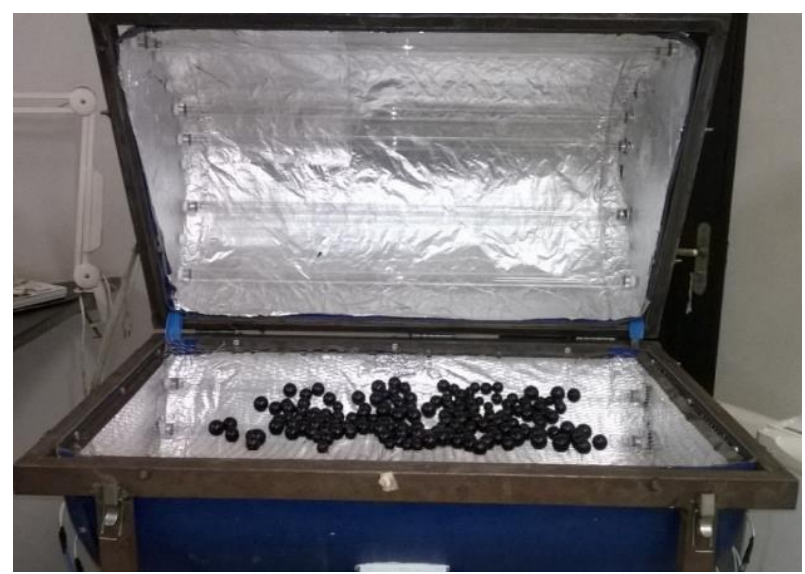

Figura 1 - Protótipo irradiador com as jabuticabas no Laboratório de Secagem e Armazenamento de Produtos Vegetais, UEG-CCET.

Os dados foram submetidos à análise de variância e, quando significativos $(\mathrm{p}<0,05)$, foi realizada a análise de regressão. Para as análises estatísticas, utilizou-se o Software SISVAR 5.3 (Ferreira, 2014).

\section{Resultados e Discussão}

Frutos irradiados e não irradiados com UV-C apresentaram o mesmo número de dias de conservação pós-colheita (Figura 2), perdurando em condições de consumo somente até o oitavo dia de armazenamento $\left(12^{\circ} \mathrm{C}-80-90 \% \mathrm{UR}\right)$, quando começaram a perder suas características desejáveis ao consumo humano. Assim sendo, a utilização da radiação UV-C não interferiu na conservação da jabuticaba, pois se observou mesmo comportamento no tratamento que não a recebeu. Pela Figura 2, nota-se o comportamento da perda de massa fresca da jabuticaba durante os oito dias de armazenamento em embalagens de polipropileno a 12 ${ }^{\circ} \mathrm{C}$ e $85-90 \%$ UR. Observou-se uma interação significativa entre as doses de irradiação utilizadas e os dias de armazenamento. A perda de massa foi comum a todos os frutos, independente do tratamento submetido (com ou sem UV-C). Porém, as maiores porcentagens de perda de massa fresca foram notadas nos frutos submetidos aos maiores tempos de exposição à radiação UV-C e, a menor, aquela que não foi exposta (Figura 2).
O aumento da perda de massa fresca durante o período em que o fruto é armazenado é explicado por Mota et al. (2002), pela perda de água durante o processo de transpiração, que é comum nos vegetais, como também pelo processo de senescência, que já se iniciou com o processo do amadurecimento do fruto. Nesse processo metabólico, reduz-se a quantidade de água no interior da célula, levando o fruto à redução da turgidez, à depreciação visual e, consequentemente, à redução da aceitabilidade comercial (Chitarra e Chitarra, 2005).

Para a firmeza das jabuticabas armazenadas, houve diferença significativa apenas para os dias de análise. A redução da firmeza dos frutos foi comum a todos os tratamentos, à medida que se aumentou os dias de armazenamento (Figura 3). Ao longo do armazenamento, observou-se uma queda da firmeza, que variou entre 20 e $8,33 \mathrm{cN}$, sendo os frutos que mais perderam aqueles que foram mais expostos à radiação UV-C, e, os não expostos, os menos afetados com a redução de firmeza, coincidindo com o comportamento da perda de massa fresca.

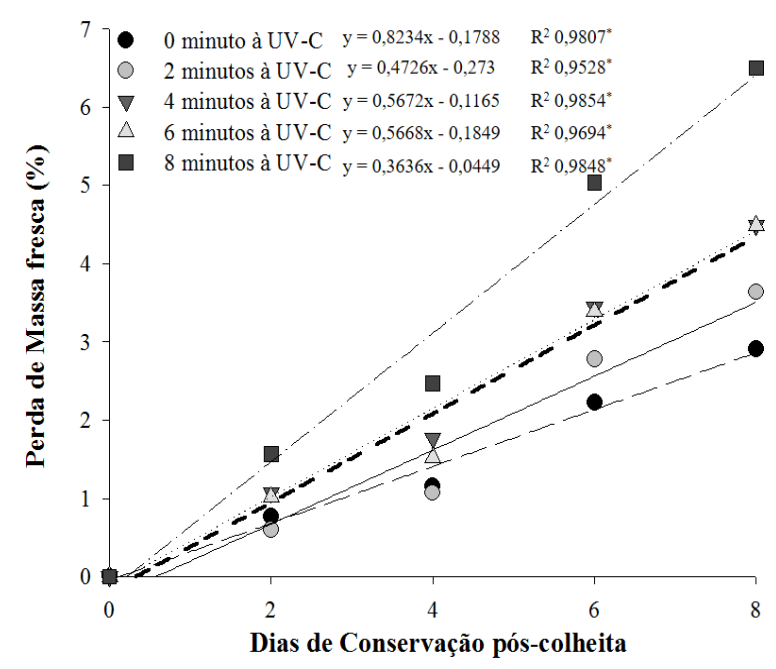

Figura 2. Interação para perda de massa fresca (\%) e conservação pós-colheita (Dias) da jabuticaba irradiada com UV-C ao longo do armazenamento.

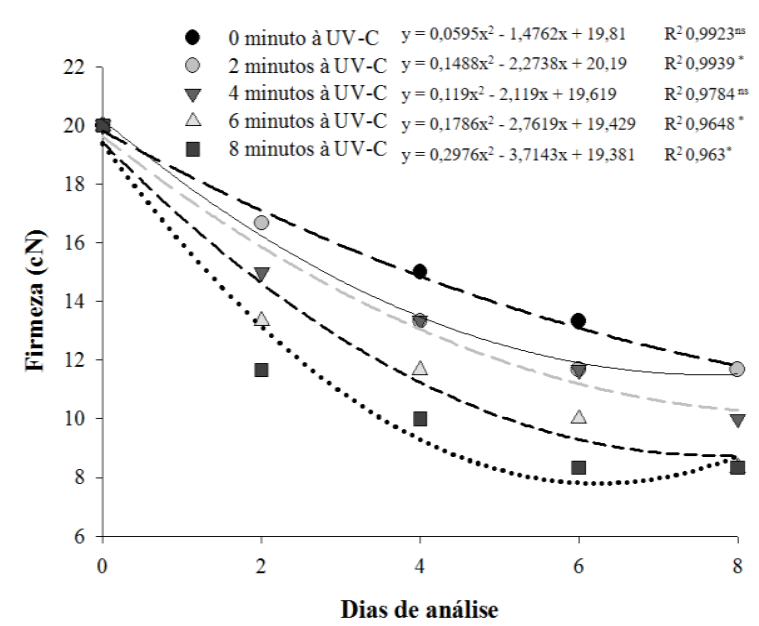

Figura 3. Variação da firmeza $(\mathrm{cN})$ da jabuticaba irradiada com UV-C ao longo do armazenamento. 
Essa redução da firmeza dos frutos é explicada pela diminuição da turgência, decorrente da redução da massa fresca, perda d'água, hemicelulose e celulose ao longo do armazenamento (Chitarra e Chitarra, 2005; Gonçalves et al., 2006). Isso ainda é justificado principalmente pela queda acentuada de pectina, que ocorre com o avançar do processo de maturação na jabuticaba (Magalhães et al., 1996). A perda da firmeza de frutos durante o seu amadurecimento implica em modificações de polissacarídeos da parede celular, o que influencia diretamente na suculência da polpa dos frutos (Yamamoto et al., 2011).

Considerando-se que é através da união de substâncias pécticas com alguns polissacarídeos que ao se ligarem estabilizam e reforçam a estrutura da parede da membrana celular, esse tipo de ligação promove maior coesão nas células, principalmente da casca do fruto (Mota et al., 2002) ao longo do armazenamento.

Observou-se interação dupla significativa entre os tempos de exposição à radiação e os dias de análise na jabuticaba. As jabuticabas irradiadas apresentaram, ao longo do armazenamento, oscilação dos teores de sólidos solúveis para todos os tratamentos, culminando numa redução ao final do armazenamento. A redução foi menor naqueles tratamentos que receberam menos tempo de exposição à radiação UV-C, apresentando maior estabilidade nos valores médios de sólidos solúveis durante o experimento (Figura 4). Os frutos do tratamento sem radiação apresentaram $15,6^{\circ}$ Brix e, no oitavo dia de armazenamento, chegaram aos 15,23 ${ }^{\circ}$ Brix; já o tratamento que mais recebeu radiação, 8 minutos, no último dia de análise chegou aos $13,1^{\circ}$ Brix, fato também observado por Vieites et al. (2011), que notaram queda no teor de sólidos solúveis da jabuticaba 'Sabará' armazenadas sob diferentes temperaturas. Isso corrobora também com dados encontrados por Daiuto et al. (2009), que, ao tratarem hidrotermicamente jabuticabas, notaram, ao final do armazenamento, decréscimo no teor de sólidos solúveis. Essa redução dos solúveis deve-se, principalmente, ao consumo destes como substrato energético para a transformação e continuação da sobrevivência do fruto (Fonseca et al., 2003).

Para acidez titulável, houve, em todos os tratamentos, acréscimo até o sexto dia de armazenamento. A partir do sexto dia, apenas os tratamentos sem radiação, 2 e 4 minutos de UV-C, mantiveram aumento no teor de acidez titulável, enquanto os demais demonstraram decréscimo até o oitavo dia de análise (Figura 5).

$\mathrm{Na}$ maioria dos frutos, a acidez titulável decresce ao longo do armazenamento, principalmente em decorrência da evolução da maturação (do processo respiratório ou de sua conversão em açúcares). Contudo, em alguns casos, ocorre o aumento da acidez titulável, pois é sabido que ácidos orgânicos são sintetizados de açúcares ou por meio de oxidações, descarboxilações ou carboxilações de outros ácidos, principalmente do ácido poligalacturônico, sintetizado pela hidrólise da pectina (por meio das enzimas poligalacturonase e pectinametilesterase), como também pela produção de compostos ácidos intermediários durante o ciclo de Krebs (Chitarra e Chitarra, 2005), fato observado para esse experimento. Blum et al. (2008), trabalhando com caqui 'Giombo', também observaram aumento da acidez titulável.

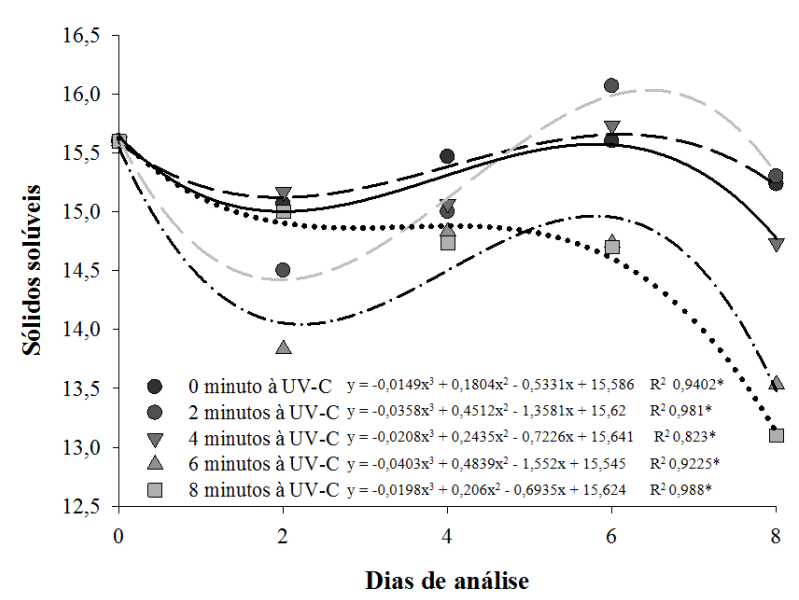

Figura 4. Variação dos sólidos solúveis ( ${ }^{\circ}$ Brix) da jabuticaba irradiada com UV-C ao longo do armazenamento.

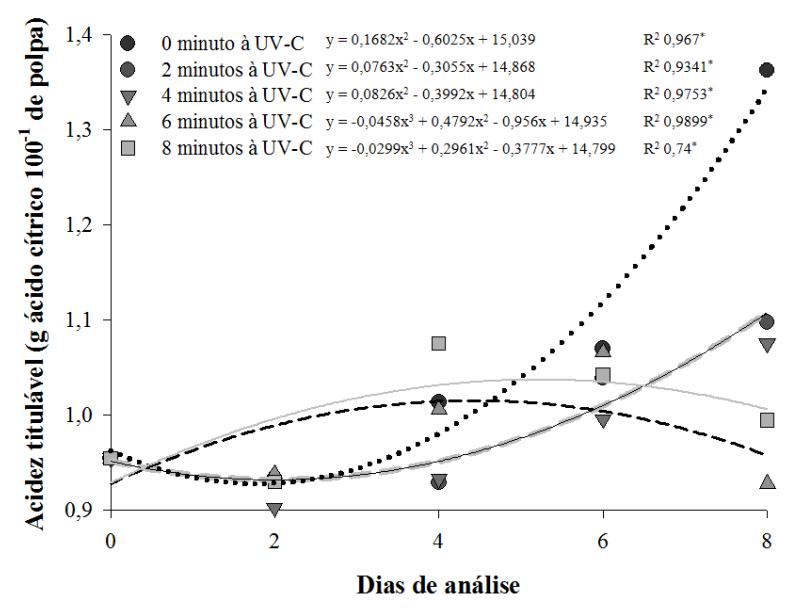

Figura 5. Variação da acidez titulável (g ácido cítrico $100 \mathrm{~g}^{-1}$ de polpa) da jabuticaba irradiada com UV-C ao longo do armazenamento.

Para o pH das jabuticabas, nota-se uma interação dupla significativa entre os fatores estudados, demonstrando, ao longo do armazenamento, comportamento semelhante em todos os tratamentos; do segundo ao sexto dia apresentou elevação nos valores de pH e diminuiu após o sexto dia de armazenagem (Figura 6). As jabuticabas expostas a 6 minutos de radiação UV$\mathrm{C}$ foram as que apresentaram maior $\mathrm{pH}(4,44)$ no sexto dia de análise, seguidas pelas expostas a 2 minutos, que chegaram a um pH médio de 4,38. O tratamento que 
apresentou o maior pico de $\mathrm{pH}$ foi justamente o que apresentou o menor valor ao final do armazenamento (6 minutos). Daiuto et al. (2013) encontraram valores de pH para jabuticabas tratadas por hidrotermia, que variaram de 3,45-3,55, sendo valores abaixo dos encontrados para esse experimento. Essa variação encontrada pode ser devido à composição físicoquímica da fruta, que varia conforme o solo, clima, irrigação e adubação a que é exposta durante o cultivo.

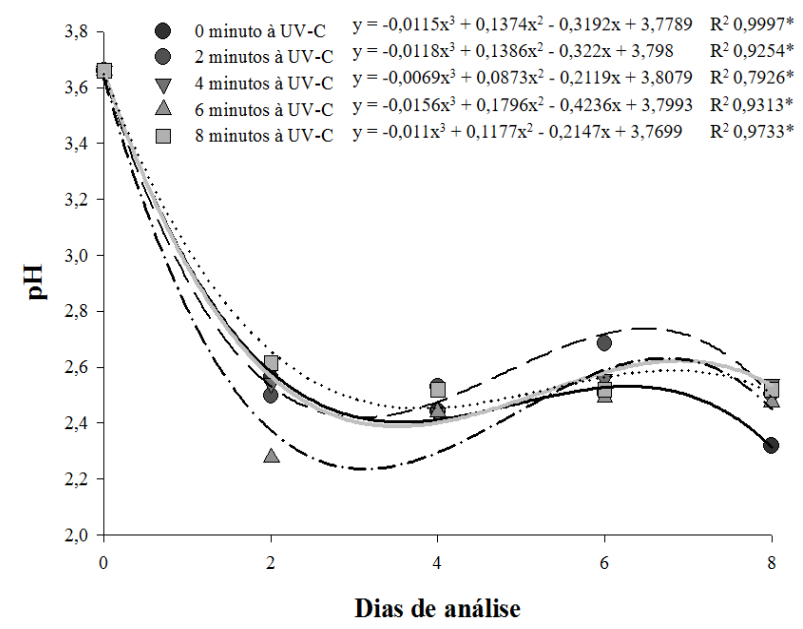

Figura 6. Variação do $\mathrm{pH}$ da jabuticaba irradiada com UV-C ao longo do armazenamento.

\section{Conclusões}

A utilização da radiação UV-C não interferiu positivamente na conservação da jabuticaba 'Sabará'.

\section{Agradecimentos}

À Capes, pela concessão da bolsa de estudos e ao Produtor de Jabuticabas Paulo, pela concessão dos frutos.

\section{Referências Bibliográficas}

Alezandro, M.R., Dubé, P., Desjardins, Y., Lajolo, F.M., Genovese, M.I., 2013.Comparative study of chemical and phenolic compositions of two species of jaboticaba: Myrciaria jaboticaba (Vell.) Berg and Myrciaria cauliflora (Mart.) O. Berg. Food Research International, 54, 468-477.

Alothman, M., Bhat, R., Karim, A.A., 2009. UV radiationinduced changes of antioxidant capacity of fresh-cut tropical fruits. Innovative food science \& emerging Technologies, 10, 512-516.

Bartnicki, V.A., Valdebenito-Sanhueza, R.M., Amarante, C.V.T., Castro, L.A.S., Rizzatti, M.R., Souza, J.A.V., 2010. Água aquecida e radiação UV-C no controle pós-colheita de Cryptosporiopsis perennans em maçãs. Pesquisa Agropecuária Brasileira, 45, 124-131.
Binoti, R.M., Daiuto, E.R., Vieites, R.L., Nuvolari, C.M., Furlaneto, K.A., Ramos, J.A., Carvalho, L.R., 2013. Radiação (UV-c) na conservação de tomate 'pizzadoro' orgânico colhido em dois estádios de maturação. Revista Iberoamericana de Tecnología Postcosecha, 14, 204-216.

Blum, J., Hoffmann, F.B., Ayub, R.A., Jung, D.L., Malgarim, M.B., 2008. Uso de cera na conservação pós-colheita do caqui cv. Giombo. Revista Brasileira de Fruticultura, 30, 830-833.

Chitarra, M.I.F., Chitarra, A.B., 2005. Pós-colheita de frutas e hortaliças: fisiologia e manuseio, segunda ed. UFLA, Lavras.

Cia, P., Benato, E.A., Valentini, S.R.T., Anjos, V.D.A., Ponzo, F.S., Sanches, J., Terra, M.M., 2009. Radiação ultravioleta no controle pós colheita de Colletotrichum gloeosporioides em uva 'Niágara Rosada'. Bragantia, 68, 1009 1015.

Citadin, I., Vicari, I.J., Silva, T.T., Danner, M.A., 2005. Qualidade de frutos de jabuticabeira (Myrciaria cauliflora) sob influência de duas condições de cultivo: sombreamento natural e pleno sol. Revista brasileira de Agrociência, 11, 373375.

Daiuto, E.R., Vieites, R.L., Moraes, M.R., Evangelista, R.M., 2009. Conservação pós-colheita de frutos de jabuticaba por irradiação. Revista Iberoamericana de Tecnologia Postchosecha, 10, 36-44.

Daiuto, E.R., Vieites, R., Tremocoldi, M.A., Carvalho, L.R., Fumes, J.G.F., 2013. Pós colheita do abacate 'Hass' submetido a radiação UV-C. Revista Colombiana de Ciências Hortícolas, 7, 149-160.

Danner, M.A., Sasso, S.A.Z., Bittencourt, J.V.M., Citadin, I., Sachet, M.R., 2011. Proposta de protocolo para extração de DNA de jabuticabeira. Ciência Florestal, 21, 363-367.

Fan, X., Niemira, B.A., Prakash, A., 2012. Irradiation of fresh fruits and vegetables. Food technology, 3, 36-43.

Ferreira, D.F., 2014. Sisvar: a Guide for its Bootstrap procedures in multiple comparisons. Ciência e Agrotecnologia, 38, 109-112.

Fonseca, M.J.O., Cenci, S.A., Leal, N.R., Botrel, N., 2003. Uso de atmosfera modificada para conservação pós-colheita do mamão "Golden". Revista Brasileira de Fruticultura, 25, 537-539.

Gonçalves, C.A.A., Lima, L.C.O., Lopes. P.S.N., Prado, M.E.T., 2006. Caracterização física, físico-química e de parede celular em diferentes estádios de desenvolvimento da fruta de figueira. Ciência e Tecnologia de Alimentos, 26, 220229.

Keyser, M., Müller, I.A., Cilliers, F.P., Nel, W. Gouws, P.A., 2008. Ultraviolet radiation as a non-thermal treatment for the inactivation of microorganisms in fruit juice. Innovative Food Science and Emerging Technologies, 9, 348-354.

López-Malo, A., Palou, E., 2005. Ultraviolet Light and Food Preservation. In: Barbosá-Cánovas, G.V., Tapia, M.S., Cano, M.P., (Ed.), Novel Food Processing Technologies. CRC Press, New York, pp. 405-421. 
Magalhães, M.M., Barros, R.S., Finger, F.L., 1996. Changes in structural carbohydrates in developing fruit of Myrciaria jaboticaba. Scentia Horticulturae, 66, 17-22.

Mercier, J., Roussel, D., Charles, M. T., Arul, J., 2000. Systemic and local responses associated with UV-induced and pathogen-induced resistance to Botrytis cinerea in stored carrot. Phytopathology, 90, 981-986.

Mota, W.F., Salomão, L.C.C., Pereira, M.C.T., Cecon, P.R., 2002. Influência do tratamento pós-colheita com cálcio na conservação de jabuticabas. Revista Brasileira de Fruticultura, 24, 049-052.

Ribeiro, C., Canada, J., Alvarenga, B., 2012. Prospects of UV radiation for application inpostharvest technology. Emirates Journal of Food and Agriculture, 24, 586-597.

Sanchez, S.J.P., Eschandi, M.A., Prada, J.A., Segura, D.S., 2012. Luz ultravioleta germicida y control de microrganismos ambientales en hospitales. Revista Costarricense de Salud Pública, 21, 19-22.

Shen, Y., Sun, Y., Qiao, L., Chen, J., Liu, D., Ye, X., 2013. Effect of UV-C treatments on phenolic compounds and antioxidant capacity of minimally processed Satsuma mandarin during refrigerated storage. Postharvest Biology and Technology, 76, 50-57.

Soares, B.N., Pommer, V.C., Sarmento, M.M.B., Ribeiro, A.J.I., Araújo, P.A., Jung-Mendaçolli, S., Pereira, A.R., 2001. Jaboticaba: instruções de cultivo. Cinco Continentes, Porto Alegre.

Vieites, R.L., Daiuto E.R., Moraes, M.R., Neves, L.C., Carvalho, L.R., 2011. Caracterização físico-química, bioquímica e funcional da jabuticaba armazenada sob diferentes temperaturas. Revista Brasileira de Fruticultura, v. $33,362-375$.

Yamamoto, E.L.M., Ferreira, R.M.A., Fernandes, P.L.O., Albuquerque, L.B., Alves, E.O., 2011. Função do cálcio na degradação da parede celular vegetal de frutos. Revista Verde, 6, 49-55.

Zenebon, O., Pascuet, N.S., Tiglea, P., 2008. Métodos físicoquímicos para análise de alimentos. Instituto Adolfo Lutz, São Paulo. 